\title{
Connecting Upland Peasants to Markets and Socio-Cultural Change in Bolaven Plateau, Southern Part of Laos
}

\author{
Phosy Keosiphandone \\ (Integral Development Studies, Faculty of Management Science, Ubon Ratchathani University. Thailand)
}

\begin{abstract}
This article focuses on the impact of government policies to connect upland areas with markets by extensive infrastructure expansion. The upland areas in which most of peasants have long sustained their live from subsistence agriculture were exposed to the market oriented policies, and thus have to adapt to these changes. By applying concepts of political ecology, cultural ecology and peasants, this article presents a study about the socio-cultural change of upland peasants in one village at Bolaven Plateau, southern Laos. It illustrated an empirical analysis of factors of socio-cultural changes in the upland societies.

Under various forces of changes, the peasant's reactions were to shift from a traditional subsistence base into four modes of production: (1) upland rice cultivation mixed with cash crops, (2) subsistence crops with part time laborers, (3) full commercial crops and 4) wage laborers. In addition, the study found that the adaptations of peasants differed by ethnicity. Different ethnics adapted to the changes at different speeds but the trend went in the same direction from subsistence to commercial agriculture. The indigenous ethnic groups (Laven and Yaheun) preserved their subsistence-based agriculture with gradual attempts at cash crops, while the other groups (mainly new comers such as Lao, Taoi and Kmu) focused on a cash-oriented production.
\end{abstract}

Keywords: Upland Peasants, Markets, Socio-Cultural Change, Laos.

\section{Introduction}

Since 1986, the Lao government shifted from centrally planned economies to relying on market forces. As a result, demand for exports is increasing production and altering the crops that farmers cultivate. This study in the past about the upland people's way of life (the majority were ethnic groups) have provided conceptual as well as empirical analysis to the change in upland agriculture, revealing a path of intensification, specialization, increased agrochemical use, and mechanization. On one hand, this provides potential upland farmers with opportunities to increase their production and income. On the other hand, local farmers, especially those from ethnic groups, are exposed to risk by relying more on external factors beyond their control, such as the production inputs and markets which are often unstable.

To examine the forces of change in rural upland societies, the cultural ecology approach provides insights for elements of cultural change and adaptation to the physical and social environment. Under the scope of political ecology, there are two main actors in this transition of agriculture: the peasants and the state. Therefore, the reactions of peasants to state policies are reviewed under political ecology.

\section{Political Ecology View of Transition}

The concept of "political ecology" often addressed the degradation of land resources inter- connected with socio-economic change caused by development. The emphasis is on the importance of investigating how external structure, especially international capital and the state, impinge on decision-making at the local level. It was argued that "While the physical reasons why land becomes degraded belong mainly in the realm of natural science, the reasons why adequate steps are not taken to counter the effects of degradation lie squarely within the realm of social science" [1]. Political ecology research has tended to focus on developing countries and the ways that a marginalized population copes with a deteriorating or otherwise changing physical environment, particularly in an agricultural context, particularly the access and control over resources, the interactions of production, and the policy and decision making power as they relate to environmental adaptations [2].

Therefore, political ecology provides a useful analytical framework for researchers trying to understand the causes of socio-economic issues in resource constrained areas especially in the marginalized areas or groups of people. Given that major economical shifts have been driven by mainstream ideology such as modernization and market oriented production, political ecology provides understanding for relationships between natural resources, business and human.

\section{Cultural Ecology}

Cultural ecology is concerned with the interrelationships between human and environment. It presents the ways in which cultural change is induced by adaptation to the environment. A pioneer in this field was 
Julian Stewards when he defined cultural ecology in his book: The Theory of Cultural Change, as "a heuristic device for understanding the effect of environment upon culture."While former anthropologists saw societies as uni-linear evolution towards one main goal, i.e. from pre-literate society to civilization, Stewards argued that evolution was multi-linear. He recognized that each environment requires different adaptations and that not every culture is working towards the same "norm" [3]. Similarly, Sutton and Anderson contended that human adaptive responses are flexible. To help understand how people and cultures deal with everyday problem, requires study of human learning, sociability, intelligence and basic needs. Culture contains a number of elements, such as social and political systems, settlement patterns and technologies that are adaptive in their form and evolve as environments change. Another important element of culture is knowledge, which was created from a long learning process of adaptations, and obtained, classified and stored in oral tradition and religion [4]. Thus knowledge, as a reflection of adaptation is studied through traditional and religious practices.

Cultural change or adaptation is found by Roberta Edwards Lenkeit [5] in two primary sources: internal and external. Internal change comes in the form of fluctuations and innovations, that is, ideas and material culture items get recycled (fluctuations), and new ideas or combinations of existing things (innovations) add to an existing culture. Such creations in areas from technology to ideology contribute to changes in a given culture. According to Lenkeit, however, more influential to cultural change are those from external sources such as planned social and economic policies. For example, Lenkeit asserted, "the desire for economic gain is perhaps the biggest stimulant for change" (Ibid.).

The study of cultural ecology provides insights for human interrelationship with environment which coincides in adaptation and cultural change that are reflected in its various elements: technology and innovation, knowledge, social structure (organization, policies, power relation) and ideology (belief, attitude, behavior). Therefore, human adaptation under the forces of changes is studied by the elements of cultural change.

\section{The Nature Peasants}

Historically, when the word "peasants" was recognized in the literary world, they were perceived with a great hostility and contempt with stinking devils, beggars, robbers, etc. Similarly, in traditional Southeast Asian societies, they were seen as the lowest social class of "stinkers and fools". [6]. By the end of the $19^{\text {th }}$ century and the beginning of the $20^{\text {th }}$ century, however, peasants became significant members of society as a main contributor to the growing manufacturing industries. Consequently, the past hostility towards peasants was gradually replaced by pity. Classical scholars in peasantry, such as Shayanov, Scott and Shanin defined peasants, in their simplest definition, as small-scale agricultural producers for their own consumption by using their own family labors [7]. National political and economic systems affect peasant livelihood through regional or local authorities who control resources [8].

\subsection{Bolaven Plateau as a Golden Land of Multi-Ethnics}

\section{Study Site Context: Bolaven Plateau}

The first phrase of a famous Lao folksong: "Paksong Phun Phaen Din Kham" (Paksong: the golden land). Due to rich soil fertility, high and long lasting rainfall and humidity, a wide range of trees, fruit trees and crops can be grown well in Bolaven Plateau. ${ }^{1}$

The Bolaven Plateau, "Phu Phiang Bolaven", is located in the centre of the southern part of Laos, sharing parts of the four southern provinces: Champasack, Salavanh, Sekong and Attapeu. The Plateau elevates approximately from 400 to 1,350 meters above the mean sea level (m.s.l.). Within the plateau, many places, rivers, mountains, etc. have been given names from their characteristics and historical backgrounds. To name a few: "Thong Katai"(rabbit field) named from its rich living for rabbits. Likewise, "Huay Namsay"(clean and clear river), one in the far northern and another in the western part of the plateau, has been given names for its very clean and clear water; Some places have been given names from its legendary figures such as "Dan Sinxay" in the western lower part, believed to be a place for a cultural hero called "Sinxay", who used his magical power to fight against enemies.

The climate of Bolaven Plateau area is governed by monsoons which are characterized by high humidity and cloudiness. The wet season starts from early May to the end of October with over $90 \%$ of the rainfall up to 3,300 $\mathrm{mm}$ on annual average [9], up to $4,000 \mathrm{~mm}$ in south western area. The remaining period is the dry season with low temperatures, averaging between $18^{\circ} \mathrm{C}$ and $26^{\circ} \mathrm{C}$, however, with some rainfall almost every month. These make the forests in the plateau relatively green, and steady water flows throughout the year. Green forests, relatively cold temperature combined with many beautiful waterfall scenes and ethnicity contribute to the attractiveness of the plateau as an important natural tourism destination in the southern part of Laos. Recently, many tourism spots have emerged, became famous, and have attracted an increasing number of

${ }^{1}$ Paksong is interchangeably spoken and referred to Bolaven Plateau. 
tourists from foreign countries, e.q. Uttayan Bachieng, Sinuk Resort, Paksong Garden, Tadfall and Tad Yeung waterfalls, etc.

\subsection{Ethnic Groups and Their Settlements}

The name "bo-laven" refers to the "Laven" ethnic group which has historically dominated the region. Dominated in Bolaven Plateau are the Mon-Khmer ethno-linguistic groups such as Laven, Taoi, Suay, Yahen, Lavae, Alak, Ngae, Katang, Talieng and Katu. They are thought to be the first inhabitants of Laos in pre-historic times, and represented by many dialects and sub-cultures. This group's religion centers on the spirits of nature. In the past when there were abundant water sources everywhere in the plateau, low population density in relation to land availability and accessibility, no road infrastructure - no connection with urban centers, ethnic groups have lived wholly from a subsistence livelihood. This has also resulted from the fact that ethnic groups could not stand fighting against the French colonizer and went far away from urban areas, and the long isolation of the plateau during the Indochina war up to 1975. Therefore, subsistence farming and collecting forest products, including hunting, were the main economic activities. Obviously, some major ethnic groups in the plateau have a strong sense of identity as follows:

Laven group is believed to be the first settlers in the region, lives mainly at the centre of the region [10]. Their family system is matrilineal kinship. Their social organization and culture is based on male dominance in the worship of means of production. The group has a strong sense of identity with religious orientation to animism and ancestor worship. Beside their own tradition, some of them practice Buddhism religion by going to temples for any Buddhism events.

Taoi group originally migrated from Taoi district of nearby Salavanh province to the north [11], and therefore, lives in the northern part of the plateau. The migration was largely due to the outbreak of the disease: diarrhea, in Taoi district during 1989-1993. Even though Taoi group do "swidden" cultivation like other groups do, they like to live in the deep forest and do comparatively more hunting and gathering.

Katu group originated from the mountain chains of Toumlan district in Salavanh Province, northeast of the plateau, and lives mainly in the western part, Lao Ngam district. Their migration to the plateau was partly by a state relocation project during 1990s. Villages are settled alongside the main road, for example Huayhoun Village in LaoNgam district. Their religion is traditional animist and ancestor worship. Handicraft and weaving have always been an important part of their livelihood in addition to rice farming and mixed crops such as peanuts, beans and bananas.

Suay group settled mainly in the western and northern part of the plateau. They live mostly in ethnically mixed villages (Lao, Laven, Taoi, Katang, etc.). Their family system is matrilineal kinship. The way of life is relatively different from other ethnic groups due to assimilation to Lao groups. Thus Suay people live from a variety of occupations such as trading, retail shops, barber services, rice mill services, car services, local restaurants, etc. However, most of them plant upland rice, sweet potatoes, coffee (Robusta) and bananas. The religion is primarily animistic shamanism, but some villagers acculturate Buddhism and Christian.

Yaheun group lives scattered in the south of Xekatam and Xekhaman rivers, within the eastern part of the plateau. Their villages form a relatively small number of houses (approximately 10-40 houses). Traditional practices center mainly on rice farming cycle, even though their livelihood largely depends on hunting and gathering. Obviously, Yaheun ethnic villagers live quite peacefully together, and have some strong traditional rules.

Other groups in Bolaven Plateau are the Lao and Phuthai (Tai-Lao ethno-linguistic groups), which increase from time to time due to intermarriage and migration to the plateau for cash crop activities such as coffee, tea, cabbage, fruits and other plantations. Some moved into the plateau for their tourism, trading and related services, and live within city areas or along the main roads. The majority of these groups settle at a relatively low elevation (below 600m) and around the river basins with favorable conditions for wet rice farming. Their religious orientation is primarily Theravada Buddhism and a strong underpinning of indigenous animism (the world of spirit).

Recently, the livelihood of some ethnic groups has been altered by some resettlement projects carried out by the government. The aim was to improve general living conditions specifically for the groups who live scattered in remote mountainous areas of the plateau. Typical projects provide houses, wells or water supply, farmland, access roads, electricity nets and educational facilities (mostly primary school). Some projects also provide primary health care services and training of village leaders, for example the "Thongkalong" Development Project, $20 \mathrm{~km}$ east of Paksong city.

\section{Case Study: Nongkhuangyai Village - A Multi-Ethnic Community in Transition}

Nongkheuang Village is located at the center of the Bolaven Plateau $70 \mathrm{~km}$ far from largest city in the south: Pakse and $19 \mathrm{~km}$ from nearest city: Paksong. The Village and the Bolaven Plateau have undergone 5 significant periods of social changes: 1) pre-colonial society; 2) French colonization; 3) Phu Mi Bun revolt; 4) 
Vietnam war; and 5) introduction of NEM. The pre-colonial society was believed to characterized with subsistence agriculture, morality, and social order. People lived wholly on agriculture, hunting and gathering activities in commune with a high degree of solidarity, mutuality and close kinship. Land, as a means of production, was owned by commune, and was not significant because of the very low population density (estimated for less than 1person per square kilometer).

The second period began in 1893 when the French first annexed territories east of the Mekong River and later annexed minor extensions of land to the west of Mekong [12]. Importantly, during this period the French colonizers experimented with coffee and rubber trees, and the plateau started to become an important agricultural area growing a wider variety of fruits and vegetables. Coffee, rubber trees and vegetables were proved to grow well in this region. However, people grew them mainly for their own consumption or barter exchange due to non-existence of formal markets. By the time of French colonization the "Phu Mi Bun" Revolt [13], erupted in 1901 and was not suppressed until 1907. It was a major rebellion by cooperation of local tribes of different ethnics under the leadership of "Ong Keo"(Krieng ethnic) and "Ong Kommadam” (Laven ethnic) against French domination. By the 1910s when rebellion leaders were killed by more advanced French army, the French took control over the plateau. As a consequence, ethnic groups settled deeper in the forest to avoid encountering the French army. To discourage attention from the French colonizer, people lived in small groups far from main roads.

The third period characterized by a great suffering during the Vietnam war. It was one of the most heavily bombed regions of the Indochina War. Controlling Bolaven Plateau was considerably strategically vital to both the Americans and North Vietnamese. Through more than three decades of civil war, people lived with poverty. Some interviewees said: "because we were afraid of bombs and being accused as a communist, we dared only cultivate a small area of rice; sometimes our rice fields were also bombed, when a smoke was seen in the forests"(Villagers, 2014: Group Discussion). Moreover, the war left most ethnic groups in a state of illiteracy because no educational services were available.

The fourth period started with the establishment of the Lao People's Democratic Republic in 1975. An initial development strategy was to bring the subsistence agricultural-based country to socialism. This was marked by the government's introduction of a central planning system, collectivization of agricultural activities, state enterprises, and other measures for reconstruction after a long period of unrest. By 1975 all the roads within the plateau were damaged by bombs. Thus, a most important government policy was to rebuild the infrastructure, particularly the roads. This collectivization process did not prove to be successful, mainly due to its inaccessibility by roads, thus leaving the majority of these upland peasants to their subsistence-based agriculture up to the introduction of New Economic Mechanism.

The fifth period of social change begins in 1986 with NEM, sometimes called New Thinking or, in Lao, "Chin Ta Na Kan Mai”, a reform process where the Lao government undertook measures to move from a centrally-planned to a market-oriented economic system [14]. The key objective of NEM includes measures to reform, stabilize, and improve the performance of the economic system, open up to foreign investment, and integrate with international economies. With respect to agriculture and rural development, the Lao government no longer provides extensive subsidies for the purpose of food self-sufficiency but commits its resources to (1) developing infrastructure to promote the development of markets and thus to increase agricultural income by providing incentives for additional cash-cropping, and (2) providing education and health services to meet the social needs of the rural population [15]. The reform clearly gives emphasis to developing rural infrastructure, such as transport, electricity, and distribution and communication networks. This market-oriented system of economy has been increasingly incorporated into the agricultural society in Bolaven Plateau, in which agriculture's main target has changed from self-sufficiency to cash income and export.

\subsection{Ethnic Culture and Population Dynamic}

At first, Nongkheuang Yai village was settled by the Laven ethnic group around 120 years ago. Then, it was getting larger from natural growth and the immigration of Taoi, Kamu, Yaheun and Lao groups. Since the first half of the 1990s, shortly after the government promoted a cash crop and market economy, the Lao group also moved into this village mostly for their coffee plantation and retail trading activities. The village became multi-ethnic with different cultures. Each group still speak their old languages, however, they can still communicate because the languages are not that much different.

The majority believe in a ghost and in Buddhism. Some people, mostly Taoi, are Christian Roman Catholic (Mr.Khamsone, 2014: interview). Religious practice is totally on voluntary basis. Yaheun group seems to have more strict traditions. For example, strangers are strictly prohibited from entering their rice field during rice planting and harvesting. When a family member is sick and sleeps in the house, a sign is put on the house entrance or stair ladder, meaning that no guest is allowed to enter the house. If a stranger gets in that house, it is believed that the sick person may get worse or even die (Mrs.Van, 2014: Interview). Similarly, when a child is born, it is strictly prohibited within 7 days for other people to enter the house, except for family members. A 
kind of fish called "Pa Kang" and a wild animal such as a barking deer is prohibited for eating, even though accidentally caught in a fish net or by traps. Ceremonies of births and blessing of new houses are, in general, similar. For example, it includes invitation of friends and close relatives to join a lunch or dinner in the host's house. Foods are made of chicken, pork, cattle or other animal meats, served with locally made brewery "Lao Hai" or beer. In ritual practices, candles and flowers are offered to the ancestors or unseen powers in order to pray for a good life (good health, luck, happiness and prosperity). In contrast, funeral practices are quite different. That of Yahean group rarely changes over time like other groups do.

While other groups acculturate Buddhist practices after death, e.q. burning the dead body and putting the rest (unburned bones) into a "Jae Dee" at the nearby Buddhist temple, Yaheun ethnic group put unburned dead body in a wooden box inside a small wooden hut or morgue built in the graveyard. Taoi ethnic group put this into a grave (primary burials), marked with stones circled around the burials. In the past, this practice was also common for Laven group. However, it became rare, since most of them follow Buddhist practices that principally use graveyards only for burning the dead body. Partly, this is because health officials and NGOs recommend them to burn the dead body, in order to prevent deceases from spreading out. Additionally, the changes in funeral practices resulted from the widening of the road side and the construction of electricity lines that invaded graveyard areas combined with the land entitlement surrounding former graveyards. An important tradition is the belief that a parent's rituals will stay at which house they died. Therefore, if a parent passes away in a particular house, that house must be given to the dead. All other family members have to build and move to a new house. That is why some old houses are commonly seen inside the community without any people living in them. The houses are left empty and untouched forever. Nowadays, since residential area is limited, this Laven tradition has gradually disappeared. Marriages are commonly between villagers in the same areas or nearby communities, no matters of ethnic background. In the past, after getting married, the young went to live with his wife's family. Nowadays, it becomes more flexible, depending on where they can have a better life (mostly depending on land availability for cultivation). Interestingly, no village member has ever moved to urban areas. Senior villagers found that: "urban life is too expensive, especially land and house. In addition, urban life depends solely on cash income from occupations other than agriculture; even though city life may be good, but we don't know and don't dare to live there." (Senior Villagers, 2014: Group Discussion).

Marriage in the Laven group is comparatively easier than that of others. It doesn't need much "Sin Sot" such as a number of buffaloes, cattle or gold to be paid or handed over to the groom's family by marriage, if the bride's family is quite poor. However, such "Sin Sot" is to be paid only if the husband desires to separate at some point in their family living. If the couple doesn't separate there is no need for "Sin Sot" at all.

Despite their different religions, they live peacefully together. Collective activities are also observed in most social and cultural events such as births, marriages, funerals and celebrations of harvest. No matter which ethnic group they are, people just invite others to join their events. Most of those invited, show their happiness to join the events. Buddhist New Year is only celebrated by all groups at the same time. It was reported that, recently, more people go to Buddhist temple at nearby villages. When being asked in interviews, two of the four village heads requested the government to help establish a Buddhist temple in the village. The relatively peaceful living attributed, firstly, from regular village meetings (once a month) to openly speak out for any concerns and problems which are then discussed and solved on a friendship basis. Secondly, village administration heads work closely together to solve any incurred problems. More importantly, all interviewed villagers say the same thing: "nothing to fight against another", "bad persons will get penalty by law" and ethnic groups respect others, invite others to attend their traditional ceremonies. In addition, by establishment of village, all village population swore that "bad person will get worse live by the power of nature Nongkheuang pond" A belief in this power after swearing has added to mutual trust, understanding and friendship. These rules work well in the heart of many original villagers, while newcomers (migrants) and some young children may not follow the rules well.

Having a population of 1,301 people, of which 669 are female, with 243 households (2014), NongkheuangYai Village has been one of the large villages. For centuries, upland peasants have sustained themselves with subsistence based agriculture. Natural increase of population in NongkheuangYai has been nearly $2.5 \%$ a year. Over the one hundred years of existence up to the beginning of the market economy in the late 1980s, population number has steadily increased, but no fear or complaint of "not having enough to eat." Since 1987 high population increase was mainly because of immigrants from other regions, particularly since the promotion of a market economy by 1986. Since then, over a period of nearly 40 years, population increased by $13.4 \%$ a year, far exceeding that of natural growth (2.5\%) (Village heads, 2014: Group Discussion). Newcomers to the village are clearly in search of fertile land for cultivating mainly coffee, and some for cabbage, which have had good prices by the middle of 1990s. Typically, immigrants have prepared good funds to buy land, whenever native villagers want to sell it. 


\subsection{Recent Infrastructure and Land Use Change}

The road passing through the village has for more than 30 years been in bad condition, even worse during the long lasting rainy season (8-9 months), before it was paved just by the beginning of 2013. It takes just 10-20 minutes to go to the city of Paksong, while it took hours in the past. Merchants also visit village more frequently. Improved road network allows easy access to markets, information and technology as well as health clinics and schools. Telecommunication net work has been well established for nearly 10 years now. No complaints about the mobile network coverage, however, some villagers say that "it is costly to have mobile phone; another cash demand for your pocket."

Infrastructure improvements have provided incentives for private entrepreneurs to invest in agriculture for export which has also been the intention of local and central government for decades. Table 1 showed that almost half $(45.2 \%)$ of village land has been given to private companies for the concession period of up to 50 years, with the possibility of extending the period [16]. Under these circumstances, villagers should focus on land for agriculture of about 53\% (729 ha) and communal land of 7.3\% (100ha), making up to 829 ha for a population of 1301 persons. However, communal land does include land for funerals ( 2 ha) and hilly terraces (52 ha) with rocks and stones which can hardly be used for agriculture, except for hunting and gathering of NTFPs.

Table 1: Distribution of Village Land Use

\begin{tabular}{|c|c|c|}
\hline Type of Usage & (ha) Area & $\begin{array}{ll} & \% \\
\text { Share } & \\
\end{array}$ \\
\hline 1.Residence & 20 & 1.5 \\
\hline 2.Land for agriculture* & 729 & 53.3 \\
\hline - upland rice & 90 & 6.6 \\
\hline - paddy rice & 10 & 0.7 \\
\hline - coffee & 330 & 24.1 \\
\hline - upland rice mixed with coffee and other crops & 239 & $\mathbf{1 7 . 5}$ \\
\hline - rehabilitation from swidden cultivation & 40 & 2.9 \\
\hline 3.Under concession for private companies & 619 & 45.2 \\
\hline $\begin{array}{ll}- & \text { Daoheuang Company }\end{array}$ & 150 & $\mathbf{1 1 . 0}$ \\
\hline 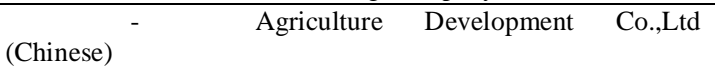 & 60 & 4.4 \\
\hline Vietnamese Company & 109 & 8.0 \\
\hline Other companies (Lao+ India) & 200 & 14.6 \\
\hline 4.Communal Land & 100 & 7.3 \\
\hline Total & 1,368 & 100.0 \\
\hline
\end{tabular}

Source: Interviews conducted by researchers in 2014.

Village land, according to a land tax payment figure, is 350 ha including farm land (there is not yet a better official figure available). However, village land should be much more than this official figure. First, following interviews, most households, except newcomers, report that they have more than 3 ha farmland. That means with 243 households, there should be more than 700ha. Second, report of land area is based on individual estimation, which can differ from the actual size. Soil characteristics and land use in NongkheuangYai village have close similarity with the general condition of Bolaven Plateau. The basaltic soil, derived from long past erupted volcano, has relatively high fertility. In addition, the evenness of the land surface prevents soil quality from declining. Long lasting high level of rainfall has also added to maintain the natural fertility rate of soil in the area.

The electricity network within the village was completely built by the middle of 2012 with approximately $50 \%$ community share of cost. Firstly, it was the intention of government to let communities share the cost of infrastructure expansion with the hope for a sense of ownership among community members. Secondly, the central, as well as the local government, has a limited budget. This means focus must be on what communities would not be willing, or not able to share, such as health care and education services.

There is a primary school direct within NongkheuangYai village, established since 1985, which has served more than 200 school children over its normal capacity. Recently, a new school building is under construction by the Ministry of Education. This new primary school was completed (August 2013), and provides 250 more pupils of class 1 to 5 . There are three secondary schools available at the distance of 2,4 and 5 kilometers from this village. Remarkably, the rate of pupils continuing secondary school is as low as $60 \%$. More importantly, less than half (50\%) of pupils who finish high school (grade 12) go to study at the universities or vocational schools. It has repeatedly been reported that it is difficult to enter university or vocational schools. Firstly, because universities can provide only limited numbers of students. Secondly, it is beyond the household's abilities to cover all study costs for their children. Moreover, not a few of the interviewees see that it is also not easy to get good work after they finish their study. Therefore, it can be a lesser incentive for households in Nongkheuang Yai village to explicitly invest in higher education. 
With regards to land use change, even though a number of communities in Bolaven Plateau have undergone a period of changes, the collective era from 1975 to 1986, Nongkheuang Yai Village, due to its remoteness and difficult road access, has not experienced collectivization. ${ }^{2}$ Therefore, land holding has mainly inherited cultural practices. In the past up to the last 20 years, when population was small and land was plentiful, households could occupy and clear land for their agriculture depending solely on the basis of labor availability. No land was sold. For example, the Taoy ethnic group migrated to NongkheuangYai village in 1989 and received nearly 40 hectares of land for agriculture for free (Villagers, 2014: Group discussion). Among the four types of land usage, land area for residence is small compared to the number of households. That means around 65 people per hectare in 12 households per hectare of residence land despite the plentiful amount of land, especially in the long past. This high proximity of households to each other resulted from the cultural behavior of close relationships among families and the fear of supernatural creatures or evils in the near forest.

Following LFA implemented during the last half of the 2000s, much of the forest areas in NongkheuangYai has been officially identified and dedicated to reserve forest (533 ha) and protection forest (44 ha). Since then, these two types of forest are protected by law, so that any agricultural activity becomes prohibited. Recently, 350 ha of land for agriculture has been officially registered by villagers. Therefore, the village head reported only the official figures of agriculture land for 350ha. The areas in the upland, where "swidden" cultivation is not operating, is recognized as communal and collectively managed by the communities. Land under this category has not yet been granted to individuals or communities and it is still recognized as state property. Stipulated in the land regulation, each family worker can hold up to 3ha of land and the user right will cease if, within three consecutive years no activity occurs on the given land. In addition, land under communal management is decreasing from time to time because of land concessions to investors. Thus, Nongkheuang Yai village holds 100 ha of communal land in 2014.

Empirical data reveals that, within the last 20 years, farmland has decreased from more than 4 ha per households in 1993 to 3.25 ha in 2014. Consequently, agriculture land also decreased continuously from more than 0.8 ha per capita to 0.68 per capita from year 1994 to 2014 respectively. Even though the declining rate is moderate, the trend will be severe as the population the recently increased dramatically, both from natural birth rates and from the migration of population from other regions searching for fertile land for cash crop opportunities. Actually, there are many more families from nearby districts and urban areas searching for land for coffee plantation and buying land from villagers, but they are not registered as NongkheuangYai villagers.

With a basic scarcity of land, this resulted in high increases of land price. Within the last 6 years, the land selling price has more than doubled from 280 US\$ in 2008 to 700 US\$ in 2011 and 11,000 US\$ in 2014. If demand of land for cash crops cannot be absorb by other land areas, the land price will most probably continue to surge higher. Within the last 20 years, it is clear that households with 4 or more plots of land has decreased from 11 to 2 households, in parallel with the increase of households with a smaller number of land plots.

\subsection{Policies-induced Change}

Given the weakness, from a political ecology point of view, of social movements at a local and grassroot level, the central power to play for the access and control over natural resources is the state. In a global era, the state is not the only actor at the national level, but is interconnected to regional and international communities. Thus, policies and measures that affect the local level have strongly been influenced not only by the shift from plan to market and from subsistence to modernization, but also by the external structure. Following this neo-liberal ideology, the Lao government put its utmost efforts these past decades to realize the transformation from subsistence to market-oriented production emphasizing investment in infrastructure and technology, market connections, as repeatedly mentioned in the National Socio-Economic Development Plans [17].

Noting that private ownership of land is a norm in market economies, and incentives associated with property rights in privately owned land, land is usually regarded as one of the factors conducive to efficient agriculture. Therefore, since the beginning of a pro-market policy in 1986, privatization of land was among the first items on the agenda. NongkhuangYai villagers, due to the absence of electricity and telecommunication net during 1980s-1990s, knew very little about state promotion for a market driven economy. More importantly, perhaps, it was the difficult accessibility by road that made trading nearly impossible, thus leading rural villagers to continue with their subsistence living.

Considering the expense of improving the infrastructure and limited sums available for public expenditure, the Lao government promoted foreign and domestic investment into the Bolaven Plateau region with the hope that investors would contribute to improving road conditions for their own benefits. Included in these investment campaigns were, according to the Law on the Promotion of Foreign Investment in Lao PDR, long term land concessions with relatively low payment, tax exemption on profits for the initial years of investment in agriculture or forestry (up to 7years), $0 \%$ import tax for the investment of goods and machineries,

${ }^{2}$ During the collectivization process, land was not owned by any private person, but by the community. 
and nearly $0 \%$ tax for the processing and export of agri-business. In this process, market led policy did not come directly to Nongkhuan Yai village, but through private enterprises and the improvement of road connected to the urban markets.

For technology improvement in agriculture, the government implemented low tariffs for the import of agricultural machineries, equipments, fertilizers, new seed varieties, and insecticides, even tax exemption on the above mentioned items for registered private entities. Processing industries were also promoted to absorb seasonal or access employment from rural areas with the expectation that mechanization of rural agriculture would follow because of labor shortages. Various local trading and distributing channels are well promoted to facilitate connection between rural villagers and national and international markets. Examples are the association of coffee traders, middlemen merchants that buy raw products at the villages, and the association of cabbage traders. In addition, mobile Vietnamese traders with motorbikes and Chinese retailers serve rural villagers with full household items, despite foreign citizens being prohibited from retail trading activities, by Lao business law. Another market facilitator for agricultural products is the state-sponsored exporting via contract farming agreements with neighboring Thailand.

Infrastructure expansion in the rural upland areas has been a policy tool with the expectation of reducing poverty. An expansion of infrastructure, particularly the road network, allows the rural population easy access to information, markets, technology, as well as health care and educational services. At the same time, it also benefits merchants and traders, officials and financial providers by allowing them easier access to integrate them with urban centers. NongkhuangYai Village experienced not only improvements in the road system, but also in electric and telecommunication networks within the last few years. Electricity provides rural villagers with high speed global information through television. Market access and information have strong impact on household decisions as to what to purchase and what can be sold for income. The distance to the nearest market, $19 \mathrm{~km}$ to Paksong city, has not been changed, but the road condition has dramatically altered. While it was almost impossible to transport products by conventional trucks before, since 2012 it takes only a few minutes to reach the city at any time of the year. While few motorcycles were owned by NongkhuangYai villagers ten years ago, today almost every household owns one or more motorcycles. Some 10 households even own pickup trucks and many more “Lot E Taen”(Villagers, 2014: Interview).

Roads provide better access to, and more opportunities to integrate with urban centers, but they can also have a negative impact on rural communities if they are not well prepared to deal with increased cash demand. In most cases, household's demand for cash will end up with shifting decision from subsistence to more cash-oriented production. In other cases, rural villagers may try more intensive hunting and gathering of NTFPs for selling, since more contacts to urban centers allowing them to sell those products easier. However, NongkhuangYai villagers have some other options for earning cash income: to work as part time laborers at the surrounding coffee farms of large investors. Thus, hunting and gathering only play a limited role for this community.

\section{Driving Forces for Changes}

Inspired by the "development" goals and accelerated by globalization, the most influential factors were rooted in a series of government policies that began with the NEM of the Lao PDR since 1986. This policy reform created structural and legal frameworks to move from a "top-down" approach in central planned economy to a liberalized market economic system.

First, rural development programs focused on poverty reduction in the upland region, promote replacement of subsistence agriculture by commercial and cash crops production. Therefore, many attempts at infrastructure expansion have been undertaken to facilitate local, national and regional trading and connectedness. The construction of a road passing through NongkhuangYai village is a clear example of connecting this rural community to new markets. Therefore, rural infrastructure expansion was found to be one of the main factors driving the transition of upland agriculture.

Second, the promotion of private investment in export oriented agriculture in the upland region had two effects: 1) large land areas in the upland, which had served for long fallow swidden agriculture, were given to investors on a long term concession period. Empirical data in NongkhuangYai village found that almost half of the communal land was given to investors for long period concession. This physical constraint, as a wide spread phenomenon in Bolaven Plateau, forced the local population to change; 2) private investors and entrepreneurs brought industrial and innovative processes of agriculture into the upland region such as the use of tractors, machines, new seed varieties, chemical fertilizers and insecticides. Introduction of agricultural technologies facilitate land use intensity, specialization and monoculture. In this way, innovations and industries push subsistence agriculture toward transition.

Third, land entitlements, as a precondition for commercialization, has legalized land sales, and thus, encouraged residences from other areas to migrate into the upland region, in search of fertile land for cash crop 
cultivation. Combined with large land areas being for concession, land scarcity became increasingly obvious. As a result, swidden cultivation became impracticable.

Fourth, classifying many types of forest land, particularly the national reserves and protecting forests, by forest law, means that no more open forests to be cleared for swidden agriculture. Furthermore, according to land law, agriculture land without any agricultural activity for three or more successive years, will be withdrawn by the authorities. For this reason, the fallow period for upland rice cultivation is logically set for not longer than 3 years. In practice, these regulations no longer permit any cultivation on a rotational basis.

On a local basis, it was found that even natural population increase can bring about land scarcity, if land productivity improvement does not outpace the rate of population growth. Particularly, when there are no more open forests and communal land for the younger generation, the given number of land plots have to be divided up among the new members, thus each plot gets smaller from one generation to another. Smaller land plots mean less land per capita and less yield for subsistence crops. However, the NongkhuangYai village population growth is caused largely by the immigration of population from other regions with high ambitions for cash crops, particularly focused on coffee production for export.

\section{The Adaptation to Changes in Terms of Modes of Production}

NonkhuangYai villagers, be they native or newcomers, young or older, educated or not, all ethnic groups are exposed to various forces and incentives, intentionally set by the public policies, for change from subsistence to commercial based agriculture. The study found four dominant modes of production in agriculture as follows:

The first one is an upland rice cultivation mixed with cash crops which has a strong correlation to villagers native to the area, particularly the Yaheaun and Laven ethnic groups, women headed households, households with smaller land plots or land area, and with or without more than two members of working age.

The second mode of production is a subsistence agriculture combined with part time wage labor. This applies mostly to younger native villagers, families with smaller land plots or land area, regardless of their ethnicity.

A third mode of production found was the wholly commercial crops (mainly coffee and cabbage) that applies mostly to newcomers to the village, without regard to how long they have been residents: the Kmu, Taoi, Lao groups and a smaller number of Laven groups who are considerably more connected to the urban center and are relatively wealthier. People of a higher educational level are also oriented to commercialization or cash crops.

A fourth mode on an increasing trend is to work as a wage laborer to earn cash income. This is widely practiced by younger teenagers or families with smaller land plots or land area, low educational attainment and more demand for cash. This is also highly possible due to the availability of work opportunities provided by several coffee plant investors surrounding the areas, who are mostly in need of agrarian workers. The fact that a vast number of children and teenagers have dropped out of school and gotten married at a younger age has added greatly to this trend.

\section{Conclusion}

Social-cultural changes dominated in terms of modes of agricultural production, were largely influenced by the government policies to move from subsistence to commercial agriculture since 1986. This went through various factors such as infrastructure expansion, particularly the roads that connect local peasants to the markets. The promotion of private investment by grating land concession on a long term basis had limited "swidden" cultivation practice by decreasing communal land. At the same time, large scale investment had introduced the use of technology and land use intensity. Furthermore, the reform of land laws and regulations have facilitated land sale, which followed by the high influx of population into the region. Combined with the natural population increase, it resulted in land scarcity driving for social and cultural changes.

The study showed that, at the initial stage, on one hand, indigenous ethnic groups of peasants did not shift right away from subsistence to modern farming. Most of them still reserve traditional farming system, especially their rice cultivation, while at the same time trying new cash oriented agriculture within the same piece of land. This application of multiply strategies could intentionally secure smooth transition of their agriculture from shifting cultivation to market oriented activities. However, due to land scarcity, there will be little space for their traditional agriculture to provide food for their own consumption. Losing the ability to produce what to consume makes local farmers more vulnerable to risk. Thus, connecting upland peasants to the markets shall incorporate with improving their ability to cope with new challenges. On the other hand, the new comers such as Lao, Taoy and Kmu groups focused their production on cash crops. Different groups adapt to the changes at different speeds but towards the same direction, i.e. commercialization. 


\section{References}

[1]. Blaikie, P. and Brookfield, H. Land Degradation and Society, (London: Methuen Publishers, 1987 : 2)

[2]. Andreatta, S. and Parlier, A. The political Ecology of Small-Scale Commercial Fishermen in Carteret County, North Carolina, Human Organization. 69(2), 2010, 180-181.

[3]. Stewards, J., The Concept and Method of Cultural Ecology, The Theory of Cultural

Change. (Urbana: University of Illinois Press, 1955: 30-42.

[4]. Sutton, M.Q. and Anderson, E.N. Introduction to Cultural Ecology. second ed. (U K:Altamira Press, 2010: 131 - 132)

[5]. Lenkeit, E.R. Introducing Cultural Anthropology. (New York: McGraw Hill, 2001: 254-255)

[6]. Santasombat, Y. , Flexible Peasants: Reconceptualizing the Third World's Rural Types. (Chiang Mai: Within Design Co.,Ltd., 2008: 9)

[7]. ibid. 19-23.

[8]. Halperin, R and Dow, J. ed. Peasant Livelihood Studies in Economic Anthropology and Cultural Ecology. (New York: St.Martin's Press, 1977: 12)

[9]. Nippon Koei co.,ltd. and Naigai Engineering co.,ltd. The study on the integrated agricultural and rural development project in Boloven Plateau, volume II. (Vientiane: MAF, 1996: 1-2-3)

[10]. Kijbamroong, V. Kao Wa Koy Ba. (Bangkok: Dansutha Printing Limited, 2009: 335)

[11]. Ibid.: 383 .

[12]. Stuart-Fox, M. The French in Laos, 1887-1945, Modern Asian Studies. 29(1): 111, 1995.

[13]. Vongchomsy, S. History of Ong Keo's Movement. (Vientiane: Sisavat Printing, 2011: 6)

[14]. Fane, G. "Trade Liberalization, Economic Reform and Poverty Reduction in Lao PDR.”, Journal of The Asia Pacific Economy. 11 (2): 213-226, 2006.

[15]. Than, M. and Tan, L.H.Joseph, ed. Laos' Dilemmas and Options: The Challenge of Economic Transition in the 1990s, (Singapore: Institute of Southeast Asian Studies, 1997: 34)

[16]. Lao People's Democratic Republic, 2003: Land Law, Article 56

[17]. Lao People's Democratic Republic, Ministry of Planning and Investment, 2011: VIII-IX 